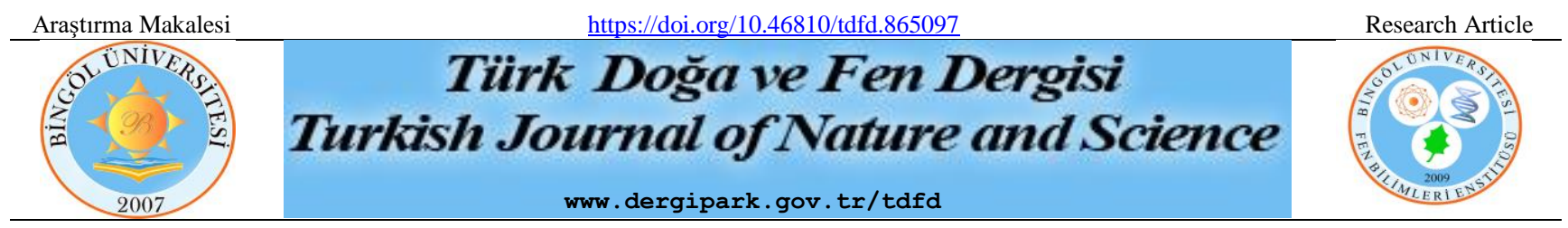

\title{
Toplum Ruh Sağlığı Merkezlerindeki Terapi Bahçelerinde Kullanılan Bitkiler Üzerine Etnobotanik Bir Çalışma
}

\author{
Fatih SATIL $^{1^{*}}$, Emine AKTAŞ ${ }^{2}$ \\ ${ }^{1}$ Balıkesir Üniversitesi, Botanik Bahçesi ve Herbaryum Araştırma ve Uygulama Merkezi, Balıkesir, Türkiye \\ ${ }^{2}$ Salihli (Manisa) Devlet Hastanesi, Manisa, Türkiye \\ Fatih SATIL ORCID No: 0000-0002-4938-1161 \\ Emine Aktaş ORCID No: 0000-0003-1624-2285 \\ *Sorumlu yazar: fsatil@gmail.com
}

(Alınış: 23.01.2021, Kabul: 29.04.2021, Online Yayınlanma: 25.06.2021)

\begin{abstract}
Anahtar
Kelimeler

Öz: Toplum Ruh Sağlığı Merkezleri (TRSM), ağır ruhsal rahatsızlığı bulunan hastaların yaşadıkları

Toplum ruh sağlı̆̆

merkezleri,

Etnobotanik,

İyileştirme

bahçeleri,

Ruh sağlığı,

Terapi bahçeleri ortamda takiplerinin ve tedavilerinin yapıldığ 1 hastanelere entegre olan birimlerdir. Bu birimlerde görevli ergoterapistlerce tedavi sürecinde hastaların ihtiyaç, istek ve becerilerine uygun olarak uygulanan aktivitelerden biri de bitki terapi bahçeleridir. Bu araştırma, Türkiye'deki farklı bölgelerden seçilen 54 TRSM'de gerçekleştirilmiştir. Bu amaçla TRSM'lerin bitki terapi bahçelerinde terapi amaçlı kullanılan bitki taksonları tespit edilmiştir. Ayrıca, özel gereksinimli bireylerin fiziksel ve bilişsel yetileri doğrultusunda terapi bahçelerindeki bu bitkilerden ne amaçla yararlanıldıkları belirlenmiştir. Çalışmada, bilgilendirici fikir birliği faktörü (FIC/IFC) ve bitki kullanım değeri (UV) hesaplanmış, ayrıca kullanılan taksonlar arasındaki farkı bulmak için Değiş̧im Aralığı (DA) formülü kullanılmıştır. Sonuçta, çalışma yapılan TRSM merkezlerinde toplam 42 taksonun terapi amaçlı kullanıldığı tespit edilmiştir. Bu bitkilerin yerel ve bilimsel isimleri, kullanım amaçları, kullanılan kısımları ve kullanım sıklıkları belirlenmiştir. Kullanımı belirlenen bu taksonlardan 14'ü otsu/soğansı, 14'ü meyve/sebze, 14'ü de çalı ve ağaç grubu bitkilerdendir. Terapi bahçelerinde en çok otsu/soğansı taksonlar kullanılmaktadır. Bitkilerin en fazla çiçek kısımlarından (\%40) görsel ve koku amaçlı yararlanılmaktadır. Kullanım amaçlarına göre bitkilerin; \%47'sinin görsellik/seyir, \%32'sinin gıda ve \%21'inin de koku amaçlı değerlendirildiği tespit edilmiştir. Çalışmanın FIC değeri 0,22'dir. UV değeri; en fazla $(0,96)$ Rosa $x$ damascena (gül), en düşük $(0,01)$ Tilia tomentosa (1hlamur) ve Abies nordmanniana (köknar)'da tespit edilmiştir. DA ise 0,95 'tir.
\end{abstract}

\section{An Etnobotanic Study on Plants Usedin Therapy Gardensin Community Mental Health Centers}

\begin{abstract}
Keywords Community mental health centers,

Ethnobotany, Healing gardens, Mental health, Therapy gardens
\end{abstract}

\begin{abstract}
Community Mental Health Centers (CMHC) are units where patients with severe mental illness are followed up and treated in the environment where they live. Plant therapy gardens are one of the activities implemented by occupational therapists in these units in accordance with the needs, desires and skills of the patients during the treatment process. This study was conducted in $54 \mathrm{CMHC}$ selected from different regions in Turkey. For this purpose, plant species used for therapy purposes in the plant therapy gardens of CMHCs were determined. Inaddition, the purpose of using these plants in thetherapy gardens was determined in accordance with the physical and cognitive abilities of the individuals with special needs. In the study, informant consensus factor (FIC/ICF) and plant use value (UV) were calculated, In addition, the Interval Range (DA) formula was used to find the difference between the plants pecies used. As a result, it was determined that total 42 plant taxa were used for therapy purposes in CMHC where the study was conducted. Local and scientific names of the plants used, usage purposes, used part sand usage frequency are determined. In the therapy gardens; 14 (33\%) taxa in the herbaceous/bulbous group, $14(33 \%)$ taxa in the fruit/vegetable group, $14(33 \%)$ taxa in the bush and tree group are used. The herbaceous/bulbous taxa are mostly used in therapy gardens. Flower parts of the plants are mostly used (40\%) for visual and fragrance purposes. Inaddition, these plants are used for $47 \%$ visual, $32 \%$ food and $21 \%$ fragrance. The FIC value of the study was calculated as 0,22 . UV is highest $(0,96)$ in Rosa $x$ damascena (rose), lowest $(0,01)$ in Tilia tomentosa (linden) and Abies nordmanniana (fir). DA is 0,95 .
\end{abstract}




\section{GíRiş}

Doğuştan ya da sonradan meydana gelen ve insanın yaşam kalitesini etkileyen ruhsal çöküntüler, hastalık ya da kaza nedeni ile oluşan sakatlıklar vb. problemlerin tedavisinde bitki ve doğal elemanların kullanılması bilinen en eski yöntemlerden birisidir.

Selçuklu ve Osmanlı dönemlerinde bazı Darüşşifalarda terapi bahçeleri tarzı peyzaj düzenlemelerinin olduğu, özel bitki tarhlarının bulunduğu ve ilaç yapımı için buralarda özel bitki ve çiçeklerin yetiştirildiği bilinmektedir [1].

Avrupa'da özellikle ikinci dünya savaşından sonra ruhsal ve fiziksel sorunlarla evlerine dönen askerlerin tedavisi için rehabilitasyon merkezlerine 1950'lerden sonra talep artmış ve rehabilitasyon merkezlerinde doğal elemanlar (bitki, su vb.) terapi aracı olarak, tedavi programlarında yoğun olarak kullanılmaya başlanmıştır. İngiltere'de 1960'larda engelli bireylerin erişebileceği "iyileştirici bahçe tasarımı" tanımlanarak, hastane bahçeleri özellikle engellilerin eğitimi ve tedavilerinde kullanılmıştır. Benzer şekilde son yıllarda Amerika ve Avrupa'daki ülkelerde, engelliler ve hastalar için terapi bahçelerinin uygulandığı birçok tedavi merkezi yapılmıştır [2].

Özellikle hastane bahçelerinde yer alan doğal alanların hastane ortamındaki kișiler üzerinde ağrı ve semptomları, ilaç kullanımını, gerginlik ve stresi azaltıcı etkilerinin varlığı yapılan çalışmalarla kanıtlanırken; zihinsel sağlı tedavisi alan hastalarda ise rahatlama, sosyalleşme ve kendine güven verici etkilerinin olduğu anlaşılmıştır [3].

Doğal çevrenin ve bitkilerin insan sağlığ etkileri ile ilgili yapılan çalışmalardan sonra insan sağlı̆̆ ve doğal çevre arasındaki ilişkiyi tanımlayan araştırmalar yapılmıştır [4]. Sonraki dönemlerde ise doğal çevrenin ve peyzajın insan psikoloji üzerindeki etkileri ve stres yönetimi, farklı çiçek renklerinin insanda oluşturduğu fiziksel ve psikolojik etkileri üzerine çalışmalar gerçekleştirilmiştir [5, 6].

Türkiye'de ise ruh sağllğ 1 ve tedavisinde terapi bahçelerini kullanımı oldukça yeni sayılır. Sağlık Bakanlığı tarafından 2006 yılında yayımlanan Türkiye Cumhuriyeti Ruh Sağlığ1 Politikas1 metni ile toplum temelli ruh sağlığı hizmetleri modeli gündeme gelmiştir. Daha soran 2011 yılında 'Ulusal Ruh Sağlığı Eylem Planı' hazırlanmış ve bu amaçla yeni bir örgütlenme ve hizmet modeli geliştirilmiştir. Toplum Ruh Sağlığ Merkezleri (TRSM) Yönergesi ile ülkenin planlanan bölgelerinde ağır ruhsal rahatsızlığı olan hastaların (özellikle bipolar, şizofreni ve kronik psikoz hastaların) tedavilerini yapmak amaciyla TRSM'ler açılmaya başlanmıștır. Terapi Bahçeleri de ülkemizde ilk defa 2008'de Bolu'da kurulan Toplum Ruh Sağlı̆̆ Merkezleri ile gündeme gelebilmiştir [7]. Sağlık bakanlığının resmi verilerine göre bugün TRSM'lerin sayıları ülke genelinde 176'ya ulaşmıștır. Bu merkezlerde; psikiyatri uzmanları, hemşireler, sosyal hizmet uzmanları, psikologlar ve ergoterapistler görevlendirilmektedir. Ergoterapistler; hastaların yaşam becerilerinde ihtiyaç, istek ve iyileşme rollerine yönelik bireysel ya da grup aktiviteleri planlaması yapmaktadır. $\mathrm{Bu}$ aktiviteler gezi, bitki, müzik, mutfak terapisi, spor ve el sanatlarından oluşmaktadır. $\mathrm{Bu}$ sayede hastaların toplumun dişına atılmadan ve dişlanmadan toplumla birlikte yaşamaları sağlanarak; yaşam kalitesini artırılması hedeflenmektedir.

Yapılan literatür çalışmalarında, terapi bahçelerinin daha çok insan psikolojisi ve sağlığı üzerindeki etkilerine yönelik yapılan araştırmalara rastlanmıştır [2-6]. Ancak hastane bahçelerinde ya da TRSM'lerdeki terapi bahçelerinde yapılmış bir etnobotanik araştırmaya rastlanmamıştır. Bununla birlikte psikolojik rahatsızlıkların tedavisinde kullanılan tıbbi bitkiler üzerinde yapılmış bazı etnobotanik araştırmalara rastlanmaktadır [8-10].

Ülkemizde 78 ilde 176 TRSM aktif olarak hizmet vermektedir. $\mathrm{Bu}$ merkezlerde hastaların yaşam becerilerinde ihtiyaç, istek ve iyileşme rollerine yönelik olarak gezi, bitki, müzik, mutfak terapisi, spor ve el sanatları aktiviteleri düzenlenmektedir. Bu aktivitelerden birisi olan bitki terapi bahçelerinde hastaların bilişsel ve fiziksel yetileri doğrultusunda çeşitli bitkilerin yetiştirilmesi, bakımı ve ürünlerin hasadı gibi uğraşlar yapilmaktadır.

$\mathrm{Bu}$ araștırmada ülkemizdeki Toplum Ruh Sağlığ Merkezlerinin bitki terapi bahçelerinde kullanılan bitkilerin yerel ve bilimsel isimleri, kullanım amaçları, kullanılan kısımları ve kullanım sıklıkları tespit edilmiştir.

\section{MATERYAL VE METOT}

$\mathrm{Bu}$ araștırma; 2020-2021 y1lları arasında gerçekleştirilmiştir. Türkiye'de aktif olarak bulunan 176 TRSM araştırmamızın evrenini, bölgelere göre dağılımına dikkat edilerek seçilen ve terapi bahçesine sahip 54 TRSM de çalışmanın örneklemini oluşturmaktadır (Şekil 1).

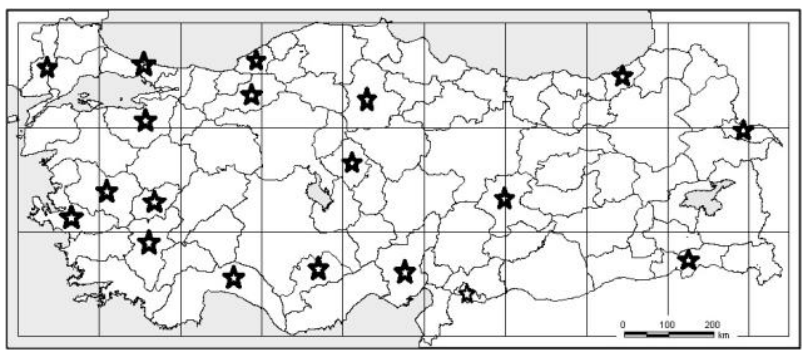

Şekil 1. Araştırma yapılan TRSM'lerin bulunduğu iller.

\section{1. İncelenen TRSM'lerin Bölgelere Göre Dağılımı}

Çalışmanın yapıldığı TRSM'lerin bölgelere göre dağılımı ve sayıları Tablo 1'de verilmiştir. 
Tablo 1. Araştırma yapıllan TRSM'lerin bölgelere göre dağılımı

\begin{tabular}{|l|l|c|}
\hline TRSM'nin yer aldığı bölge & İl & Seçilen TRSM sayısı \\
\hline Marmara Bölgesi & İstanbul & 6 \\
& Bursa & 6 \\
& Edirne & 3 \\
\hline Ege Bölgesi & İzmir & 8 \\
& Manisa & 4 \\
& Uşak & 1 \\
& Denizli & 1 \\
\hline İç Anadolu Bölgesi & Karaman & 2 \\
& Kırşehir & 1 \\
& Çorum & 1 \\
\hline Akdeniz Bölgesi & Antalya & 5 \\
& Adana & 4 \\
\hline Karadeniz Bölgesi & Bolu & 3 \\
& Zonguldak & 2 \\
& Rize & 1 \\
\hline Doğu Anadolu Bölgesi & Malatya & 2 \\
& Iğdır & 1 \\
\hline Güneydoğu Anadolu Bölgesi: & Kilis & 2 \\
& Şırnak & 1 \\
\hline
\end{tabular}

\subsection{Araştırma Verilerinin EIde Edilmesi}

Çalışma verileri, seçilen TRSM'lerde yapılan gözlemler ve bu birimlerde çalışan görevlilerden elde edilmiştir (Şekil 2). Bitki terapi bahçelerinde kullanılan bitkilerin yerel isimleri, kullanılan kısımları, kullanım amaçları ve kullanım sıklıkları TRSM'lerde görevli ergoterapistler görüşülerek belirlenmiştir. Çalışmanın kaynak kişileri bu merkezlerde çalışan ergoterapistlerdir.

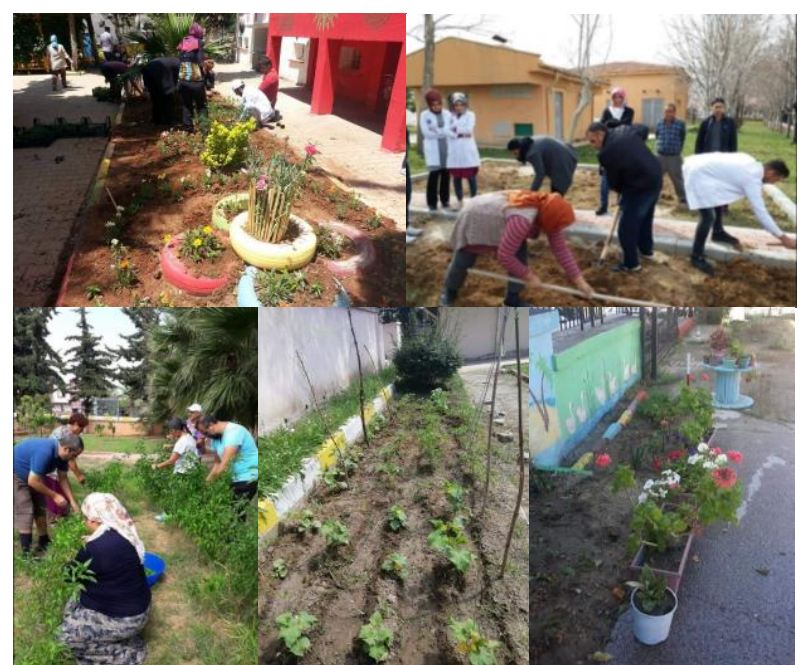

Şekil 2. TRSM'lerdeki terapi bahçelerinde bitki yetiştirme, bakım ve hasat aktiviteleri.

\subsection{Bitki Örneklerinin Teşhisi}

TRSM'lerde tespit edilen yerli bitkilerin teşhislerinde Türkiye Florası adlı eserden [11, 12]'den, egzotik türlerin teşhislerinde ise ülkemizin süs ve egzotik bitkileri üzerinde yapılmış çeşitli kitaplardan yararlanılmıştır [13-15]. Teşhis edilen bitkilerin güncel taksonomik durumları ise The Plant List'ten (http://www.theplantlist.org/) kontrol edilmiştir. Bitkilerin Türkçe isimleri hem TRSM'de çalışan ergoterapistlerden hem de yukarıda verilen kaynaklardan yararlanılarak belirlenmiştir.

\subsection{Veri Analizi}

Çalışmada, bilgilendirici fikir birliği faktörü (FIC/IFC) ile bitkilerin etkinliği belirlenmiştir [16]. Ayrıca bitkilere yapılan atıf sayısı ile de bitki kullanım değeri (UV) hesaplanmıștır [17]. FIC seviyelenmesi Kayani ve ark. [18]'na göre yapılmıştır. Buna göre FIC değeri 0 ile 1 arasında değişmektedir. Yüksek bir değer (1'e yakın) az sayıda taksonun büyük bir bilgi kaynağı tarafından kullanıldığını, düşük bir değer (0’a yakın) bilgi verenlerin bir kategoride taksonlara göre çok fazla çeşitlilik olduğunu göstermektedir.

\section{FIC $=$ Nur-Nt/Nur-1}

(Nur: Belirli bir bitki kullanım kategorisi için bilgi verenlerden gelen kullanım raporlarının sayısı. Nt: Bitkilerin kullanım kategorisiyle ilișkili taksonların sayısı)

\section{$\mathbf{U V}=\mathbf{U} / \mathbf{N}$}

(U: Bir türün aldığı atıf sayısı, N: Bitkiyi kullanan toplam kişi sayısı) Kullanılan taksonlar arasındaki farkı bulmak için Değişim Aralığı (DA) formülü kullanılmıştır [19].

Değişim Aralığı (DA): Maksimum değer-minimum değer (Maksimum değer türün aldığı en yüksek UV değeri iken minimum değer taksonun aldığı en düşük UV değerini göstermektedir).

Yüzdelik hesaplamalarında ise SPSS 24 paket programı kullanılmıştır.

\section{BULGULAR}

Çalışma yapılan TRSM'lerdeki terapi bahçelerinde, toplam 42 taksonun terapi amaçlı kullanıldı ̆̆ 1 tespit edilmiştir. Kullanılan bitkilerin yerel ve bilimsel isimleri, kullanım amaçları, kullanılan kısımları ve kullanım sıklıkları Tablo 2-4'te verilmiştir.

Elde edilen veriler çerçevesinde TRSM'lerdeki terapi bahçelerinde kullanılan bitkiler hayat formlarına göre; otsu/soğansı (14 takson), meyve/sebze (14 takson), çalı ve ağaç grubu (14 takson) şeklinde kategorilere ayrılmıştır (Tablo 2-4).

Otsu/soğans1 bitkilerde FIC değeri 0,75 'le orta seviyededir. UV açısından en yüksek değer Viola $\times$ wittrockiana (menekşe)'da 0,88'dir. En düşük UV ise 0,03 olup Primula vulgaris (çuha çiçeği)'te görülmüştür. DA değerinin $(0,85)$ yüksek olması bazı bitkilerin diğerlerine oranla daha çok kullanıldığının bir göstergesidir (Tablo 2)

Meyve/sebze grubu bitkilerin FIC değeri $0,75^{\prime}$ tir. UV değeri; en yüksek $(0,68)$ Petroselinum crispum (maydanoz)'da, en düşük $(0,05)$ ise Anethum graveolens (dereotu)'te belirlenmiştir. Meyve/sebze grubu bitkilerin DA değeri 0,63 olarak bulunmuş ve farkın orta seviyeye yakın olduğu görülmüştür (Tablo 3). 
Tablo 2. TRSM bahçelerindeki otsu/soğansı bitkilerin kullanım amacı ve kullanılan kısımları

\begin{tabular}{|c|c|c|c|c|c|c|}
\hline \multicolumn{7}{|c|}{ KATEGORILER } \\
\hline $\begin{array}{c}\text { Bitkinin } \\
\text { Türkçe adı }\end{array}$ & Bilimsel Adı & $\begin{array}{c}\text { Kullanım } \\
\text { amacı }\end{array}$ & Kullanılan kısmı & $\begin{array}{c}\text { Kullanım } \\
\text { sayısı }\end{array}$ & $\begin{array}{c}\text { Toplam } \\
\text { kullanım sayısı } \\
\text { oranı\% }\end{array}$ & $\mathbf{U V}$ \\
\hline Menekşe & Viola $\times$ wittrockiana Gams & Görsellik & Çiçek & 48 & 19.5 & 0,88 \\
\hline Zambak & Lilium candidum $\mathrm{L}$. & Koku, Görsellik & Tüm bitki, çiçek & 41 & 16.6 & 0,75 \\
\hline Fesleğen & Ocimum basilicum $\mathrm{L}$. & Koku, Görsellik & Yaprak & 39 & 15.8 & 0,72 \\
\hline Lale & Tulipa sp. & Görsellik & Tüm bitki, çiçek & 32 & 13 & 0,59 \\
\hline Karanfil & Dianthus caryophyllus L. & Koku, Görsellik & Tüm bitki, çiçek & 21 & 8.5 & 0,38 \\
\hline Kasım patı & Chrysanthemum indicum $\mathrm{L}$. & Görsellik & Çiçek & 13 & 5.2 & 0,24 \\
\hline Sardunya & Geranium sanguineum $\mathrm{L}$. & Görsellik & Tüm bitki & 13 & 5.2 & 0,24 \\
\hline Begonya & Begonia semperflorens Link\&Otto & Görsellik & Tüm bitki, çiçek & 9 & 3.6 & 0,16 \\
\hline Nane & Mentha x piperita $\mathrm{L}$. & Koku, Gıda & Yaprak & 9 & 3.6 & 0,16 \\
\hline Ayçiçeği & Helianthus annuhus $\mathrm{L}$. & Görsellik, Gıda & Tüm bitki, tohum, çiçek & 6 & 2.4 & 0,11 \\
\hline Sümbül & Hyacinthus orientalis $\mathrm{L}$. & Koku, Görsellik & Tüm bitki, çiçek & 6 & 2.4 & 0,11 \\
\hline Ateş çiçeği & Salvia splendens Sellow ex Schult. & Görsellik & Tüm bitki, çiçek & 4 & 1.6 & 0,07 \\
\hline Kadife çiçeği & Tagetes patula $\mathrm{L}$. & Görsellik, Koku & Tüm bitki, çiçek & 3 & 1.2 & 0,05 \\
\hline Çuha çiçeği & Primula vulgaris Huds. & Görsellik & Tüm bitki, çiçek & 2 & 0.8 & 0,03 \\
\hline Toplam:14(\% & & & & 246 & 100 & 4.5 \\
\hline FIC $=0,75$ & & Nur=54 & $\mathrm{Nt}=14$ & Değişiı & |ralığı (DA): 0,85 & \\
\hline
\end{tabular}

Tablo 3. TRSM bahçelerindeki meyve/sebze grubu bitkilerin kullanım amacı ve kullanılan kısımları

\begin{tabular}{|c|c|c|c|c|c|c|}
\hline \multicolumn{7}{|c|}{ KATEGORILLER } \\
\hline $\begin{array}{c}\text { Bitkinin } \\
\text { Türkçe adı }\end{array}$ & Bilimsel Adı & $\begin{array}{c}\text { Kullanım } \\
\text { amacı }\end{array}$ & $\begin{array}{c}\text { Kullanılan } \\
\text { kısmı }\end{array}$ & $\begin{array}{c}\text { Kullanım } \\
\text { sayısı }\end{array}$ & $\begin{array}{c}\text { Toplam kullanım } \\
\text { sayısı oranı \% }\end{array}$ & $\mathbf{U V}$ \\
\hline Maydanoz & Petroselinum crispum (Mill.) Fuss & Gida & Yaprak & 37 & 25 & 0,68 \\
\hline Biber & Capsicum аппиит $\mathrm{L}$. & Gida & Meyve & 21 & 14 & 0,38 \\
\hline Domates & Solanum lycopersicum L. & Gida & Meyve & 19 & 13 & 0,35 \\
\hline Marul & Lactuca sativa $\mathrm{L}$. & Gida & Yaprak & 17 & 12 & 0,31 \\
\hline Salatalık & Cucumis sativus L. & Gida & Meyve & 17 & 12 & 0,31 \\
\hline Patlican & Solanum melongena $\mathrm{L}$. & Gida & Meyve & 16 & 11 & 0,29 \\
\hline Roka & Eruca vesicaria (L.) Cav. & Gida & Yaprak & 12 & 8 & 0,22 \\
\hline Fasulye & Phaseolus vulgaris L. & Gida & Meyve & 7 & 5 & 0,12 \\
\hline Semiz otu & Portulaca oleracea L. & Gida & Yaprak & 7 & 5 & 0,12 \\
\hline Karpuz & Citrullus lanatus (Thunb.) Matsum. \& Nakai & Gida & Meyve & 6 & 4 & 0,11 \\
\hline Tere & Lepidium sativum $\mathrm{L}$. & Gida & Yaprak & 6 & 4 & 0,11 \\
\hline Soğan & Allium cepa $\mathrm{L}$. & G1da & Yaprak & 4 & 3 & 0,07 \\
\hline Misir & Zea mays L. & G1da & Meyve & 4 & 3 & 0,07 \\
\hline Dere otu & Anethum graveolens $\mathrm{L}$. & Gida & Yaprak & 3 & 2 & 0,05 \\
\hline \multicolumn{4}{|c|}{ Toplam:14 (\%33) } & 176 & 100 & 3,25 \\
\hline FIC $=0,75$ & & Nur $=54$ & $\mathrm{Nt}=14$ & Değişin & Aralığı (DA): 0,63 & \\
\hline
\end{tabular}

Çalı ve ağaç grubu bitkilerinin verileri incelendiğinde FIC değerinin 0,75 olduğu görülmüştür. UV değeri; en yüksek $(0,96)$ Rosa $x$ damascena (gül)'da, en düşük $(0,01)$ Tilia tomentosa (1hlamur) ve Abies nordmanniana (köknar)'da tespit edilmiştir. Çalı ve ağaç grubu bitkilerin DA değeri ise 0,95 'tir (Tablo 4).

Kullanım amaçları ile ilgili veriler değerlendirildiğinde; bitkilerin \%47'si görsellik, \%32'si g1da ve \%21'i koku amaçlı kullanıldığı görülmüştür. Kullanım amaçlarına göre en yüksek FIC değerini $(0,81)$ koku amaçlı kullanım, en düşük değeri de $(0,54)$ görsellik oluşturmuştur (Tablo 5).

Terapi bahçelerindeki bitkilerin gövde, meyve, yaprak ve çiçek kısımlarından yararlanılmaktadır. Kullanılan kısımların UV değeri sırasıyla; çiçek $(0,33)$, yaprak $(0,20)$, gövde ve meyve $(0,14)$ şeklindedir. FIC değeri ise en yüksek $(0,86)$ gövde ve meyvesinden yararlanılan bitkilerde görülmüştür (Tablo 6). 
Tablo 4. TRSM bahçelerindeki çalı ve ağaç grubu bitkilerin kullanım amacı ve kullanılan kısımları

\begin{tabular}{|c|c|c|c|c|c|c|}
\hline \multicolumn{4}{|c|}{ KATEGORILLER } & \multirow[b]{2}{*}{$\begin{array}{c}\text { Kullanım } \\
\text { sayısı }\end{array}$} & \multirow[b]{2}{*}{$\begin{array}{c}\text { Toplam } \\
\text { kullanım } \\
\text { sayısı } \\
\text { oranı \% }\end{array}$} & \multirow[b]{2}{*}{ UV } \\
\hline $\begin{array}{l}\text { Bitkinin } \\
\text { adı }\end{array}$ & Bilimsel Adı & Kullanım amacı & $\begin{array}{c}\text { Kullanılan } \\
\text { kısmı }\end{array}$ & & & \\
\hline Gül & Rosa $\times$ damascena Herrm. & Görsellik & Çiçek & 52 & 28.8 & 0,96 \\
\hline Ortanca & Hydrangea macrophylla (Thunb.) Ser. & Görsellik & Tüm bitki, çiçek & 37 & 20,5 & 0,68 \\
\hline Lavanta & Lavandula angustifolia Mill. & Koku, Görsellik & Çiçek & 22 & 12,2 & 0,40 \\
\hline Biberiye & Rosmarinus officinalis L. & Gıda, Koku, Görsellik & Yaprak & 21 & 11,6 & 0,38 \\
\hline Hanımeli & Lonicera etrusca Santi & Görsellik, Koku & Tüm bitki, çiçek & 13 & 7,2 & 0,24 \\
\hline Leylak & Syringa vulgaris $\mathrm{L}$. & Koku, Görsellik & Tüm bitki, çiçek & 8 & 4,4 & 0,14 \\
\hline Zakkum & Nerium oleander L. & Görsellik & Tüm bitki, çiçek & 7 & 3,8 & 0,13 \\
\hline Zeytin & Olea europaea L. & Gida & Yaprak, meyve & 6 & 3,3 & 0,11 \\
\hline Japon çamı & $\begin{array}{l}\text { Cryptomeria japonica (Thunb. ex L.f.) } \\
\text { D.Don }\end{array}$ & Görsellik & Tüm bitki & 4 & 2,2 & 0,07 \\
\hline Guara çalısı & Guara lindheimeri Engelm. \& A.Gray. & Görsellik & Tüm bitki, çiçek & 3 & 1,6 & 0,05 \\
\hline $\begin{array}{l}\text { Limon } \\
\text { servi }\end{array}$ & Cupressus macrocarpa Hartw. & Görsellik & Tüm bitki & 3 & 1,6 & 0,05 \\
\hline Palmiye & Chamaerops humilis L. & Görsellik & Tüm bitki & 2 & 1,1 & 0,03 \\
\hline Ihlamur & Tilia tomentosa Moench & Gida & Tüm bitki, çiçek & 1 & 0,5 & 0.01 \\
\hline Köknar & Abies nordmanniana (Steven) Spach & Görsellik & Tüm bitki & 1 & 0,5 & 0,01 \\
\hline \multicolumn{4}{|c|}{ Toplam:14(\%33) } & 180 & 100 & 3,33 \\
\hline FIC $=0,75$ & & Nur $=54$ & & Değișim & ralığı (DA & \\
\hline
\end{tabular}

Tablo 5. TRSM bahçelerindeki bitkilerin kullanım amaçlarının değerlendirilmesi

\begin{tabular}{lccccc}
\hline & \multicolumn{2}{c}{ KATEGORILER } \\
\hline & Kullanım sayısı & $\begin{array}{c}\text { Toplam kullanım sayısı } \\
\text { oranı \% }\end{array}$ & UV & Nt & FIC \\
\hline Görsellik & 25 & 47 & 0,46 & 25 & 54 \\
Gıda & 17 & 32 & 0,31 & 17 & 54 \\
Koku & 11 & 21 & 0,20 & 0,69 & 11 \\
\hline
\end{tabular}

Tablo 6. TRSM bahçelerindeki bitkilerin kullanılan kısımlarının değerlendirilmesi

\begin{tabular}{|c|c|c|c|c|c|c|}
\hline \multicolumn{7}{|c|}{ KATEGORILLER } \\
\hline & Kullanım sayısı & $\begin{array}{c}\text { Toplam kullanım sayısı } \\
\text { oranı \% }\end{array}$ & $\mathbf{U V}$ & Nur & $\mathbf{N t}$ & FIC \\
\hline Çiçek & 18 & 40 & 0.33 & 54 & 18 & 0,67 \\
\hline Yaprak & 11 & 24 & 0.20 & 54 & 17 & 0,69 \\
\hline Gövde & 8 & 18 & 0.14 & 54 & 8 & 0,86 \\
\hline Meyve & 8 & 18 & 0.14 & 54 & 8 & 0,86 \\
\hline
\end{tabular}

\section{TARTIŞMA VE SONUÇ}

Türkiye genelinde farklı bölgelerden seçilen 54 TRSM'deki terapi bahçelerinde yapılan etnobotanik çalışma sonucunda toplam 42 taksonun tedavi amaçlı kullanıldı̆̆ 1 tespit edilmiştir. $\mathrm{Bu}$ taksonlardan 14'ü otsu/soğansı, 14'ü meyve/sebze, 14'ü de çalı ve ağaç grubu bitkilerdendir.

Terapi amaçlı değerlendirilen bitkilerin en fazla çiçek kısımlarından (\%40) yararlanılmaktadır, bunu sırasıyla yaprak (\%24), gövde ve meyve kısımları (\%18) takip etmektedir (Şekil 3).

TRSM'ler sınırları belirli açık alan terapi mekanlarıdır. Benzer şekilde az çok çalışma alanımız gibi sınırları belirli açık alan olan Tayfur Sökmen Kampüsü ve çevresinde (Antakya/Hatay) bulunan bitkiler üzerine yapılan etnobotanik bir çalışma yapılmıştır [20]. Altay ve Karahan (2012) tarafından yapılan bu çalışmada, alanda tespit edilen 43 bitki taksonu kullanılan kısımlarına göre değerlendirildiğinde; yaprakların $\% 37,50$; meyvelerin \%17,86 ve çiçeklerin ise \%16,07 oranında kullanımının olduğu görülmüştür [20].

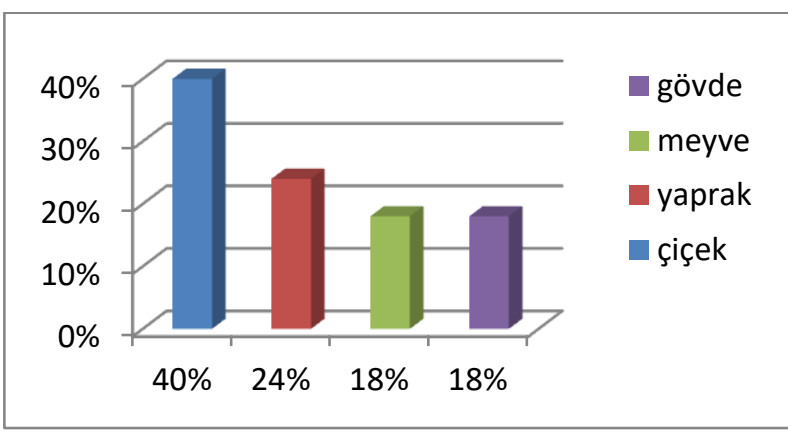

Sekil 3.TRSM'lerdeki bitkilerin kullanılan kısımları 
Bizim çalıșma alanımızdaki terapi bahçelerinde kullanılan bitkiler kullanım amaçlarına göre; gıda, görsellik ve koku şeklinde gruplandırılmıştır. Buna göre, bitkilerin \%47'si görsellik, \%32'si gida ve \%21'i koku amaçlı değerlendirilmektedir (Şekil 4).

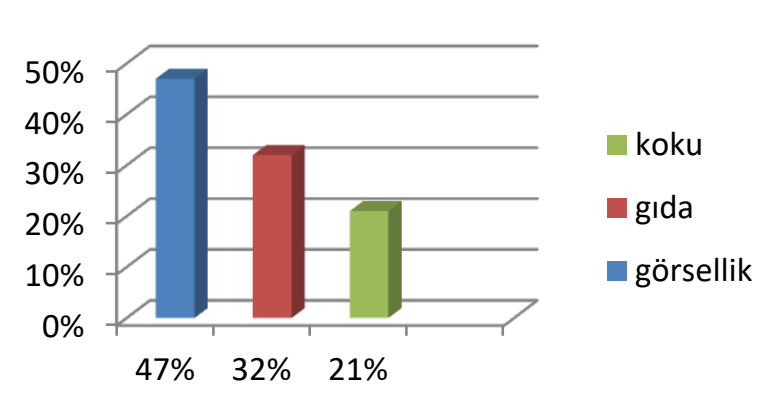

Sekil 4.TRSM'lerdeki bitkilerin kullanım amaçları

Terapi bahçelerinde kullanılan bitkilerin UV ve FIC değerleri aşağıda değerlendirilmiştir.

Bitki gruplarının UV değeri; otsu/soğansı bitkilerde 4,5, ağaç ve çalı grubu bitkilerde 3,33 ve meyve/sebze grubu bitkilerde de 3,25'tir. Buradan anlaşıllyor ki; otsu/soğansı bitkiler daha fazla kullanılmakta, bunu ikinci sırada ağaç ve çalı grubu bitkiler izlemektedir. En az kullanımı belirlenen bitki grubu ise meyve sebze grubu bitkilerdir.

Kullanımı tespit edilen tüm taksonlar içerisinde UV değerinin en yüksek $(0,96) R . \times$ damascena (gül)'da, en düşük değerin ise $(0,01) T$. tomentosa (ihlamur) ve $A$. nordmanniana (köknar)'da olduğu görülmektedir. Sonuçta UV değerinde maksimum ve minimum seviye arasında göze çarpan anlamlı bir fark (DA: 0,95) olduğu bulunmuştur. Buradan anlaşılıyor ki, terapi bahçelerinde terapi amaçlı olarak otsu/soğansı taksonlardan menekşe, zambak, fesleğen ve lale; meyve/sebze grubundan maydanoz; çalı ve ağaç grubundan da gül, ortanca ve lavanta daha fazla kullanılırken diğer taksonlar daha az seviyede kullanılmaktadır.

Kullanımı tespit edilen 42 taksona ve 54 kaynak kişi sayısına göre çalışmanın genel FIC değeri 0,22 bulunmuş olup, düşük seviyede $(\mathrm{FIC}=0-1)$ bir fikir birliğinin olduğu söylenebilir. FIC değerinin düşük olmasının nedeni, TRSM'lerin farklı coğrafik bölgelerde yer alması ve her ilde çok farklı çeşitte bitki türlerinin kullanılıyor olması ile açıklanabilir.

Çalışmamızda kullanımı tespit edilen tüm bitki gruplarının FIC değeri eşit $(0,75)$ bulunmuştur. Kullanım amaçlarına göre en yüksek FIC değerini 0,81 ile koku amaçlı kullanılan bitkiler oluştururken, en düşük FIC değerini 0,54 ile görsellik oluşturmaktadır. $\mathrm{Bu}$ da TRSM'lerde hastaların bilişsel ve fiziksel yetileri doğrultusunda bitkilerden yararlanıldığını göstermektedir. Terapi bahçelerinde kullanılan meyve/sebze grubu bitkiler hastalar için gida olarak tüketilen bir ürün olarak görülmekten ziyade daha çok işuğraş etkinliği olarak değerlendirilmiştir. Benzer şekilde meyve/sebze grubu bitkilerin yetiştirilmesi ve onlardan yemek yapılması faaliyeti hastaların ruh sağlığ üzerinde olumlu etki yaptığına dair çalışmalar mevcuttur [21, 22].

TRSM'ler dışında, ruhsal hastalıklar üzerinde yurtiçi ve yurt dışında yapılmış birçok etnobotanik çalışma bulunmaktadır. Nepal'de Parkinson hastalığına yönelik yapılan bir araştırmada 56 katılımcı ile görüşüp, 35 çeşit bitki türü tespit edilmiş ve FIC değeri 0,38 hesaplanmıştır [23]. Kuzeydoğu Brezilya Pernambuco eyaletinde, Savana bölgelerinde tedavi edici kaynak olarak bitki türleri üzerine yapılan bir araştırmada ise psikolojik hastalıklarda kullanılan bitki türlerinin FIC değerinin 0,74 olduğu görülmüştür [9]. Sinir ve psikosomatik sorunlar için Çin'de Mulam halkı tarafından kullanılan şifalı bitkiler üzerine yapılan bir etnobotanik çalışmada ise $\mathrm{FIC}=0,90$ olduğu saptanmıştır [10]. Bangladeş'in Bandarban bölgesindeki yerli topluluklar tarafindan kullanılan şifalı bitkilerin etnobotanik araştırmasında, nörolojik ve psikolojik hastalıkların fikir birliği faktörü $\mathrm{FIC}=0,50$ olarak rapor edilmiştir [24]. Benzer şekilde Malatya yöresinde yapılan şifalı bitkiler çalışmasında [8] nörolojik hastalıkların FIC değeri 0,27; Giresun Espiye yöresinde nörolojik hastalıklar üzerine yapılan şifalı bitkiler çalışmasında ise FIC değeri 0,42 bulunmuştur [25].

$\mathrm{Bu}$ çalışmanın FIC değeri ile yurt dişı ve gerekse yurtiçinde yapılmış olan ruhsal hastalıklarla ilgili çalışmaların FIC değerleri karşılaştırıldığında yurt dışı çalışmalarda daha yüksek bir FIC değeri olduğu görülmektedir [8-10, 21-25]

$\mathrm{Bu}$ çalışmamızda incelenen TRSM'lerdeki terapi bahçeleri uygulamalarında; kişinin fiziksel, zihinsel ve kişisel gelişimi için canlı malzeme olarak kullanılan bitkiler değerlendirilme amaçları; doğanın zihinde canlandırılması (seyri), bahçecilik faaliyetleri (bitki yetiştirme, meyve toplama vb.) ve yetiştirilen bitkilerin tedavi amaçlı kullanımı şeklinde gruplandırılmıştır.

Terapide kullanılan sebze, meyve ya da süs bitkisi üretim aktivitelerinin, fiziksel ya da zihinsel engelli insanlarda başarma, üretme duygusunu vererek psikolojik tatmin veya kendine güven duygularını desteklemektedir [21, 22].

Son araştırmalara göre, doğa ile iletişim halinde olmak hastalıklara sebep olan stres/depresyon gibi birçok ruhsal sorunları engelleyerek hastalıklardan korurken, bir yandan da hastalıkların iyileştirilmesinde önemli rol oynamaktadır [26]. Tabiatın ve bitkilerin insan üzerindeki tedavi edici özelliğine dair yapılmış birçok bilimsel çalışma vardır. Bitkilerin, bireyler üzerinde sakinleştirici ve ağrı kesici etkisi de bilimsel araştırmalarla ispatlanmıştır [2]. Araştırma sonuçlarına göre, bahçede ve doğada zaman geçirmek çoğu zaman ameliyatların, enfeksiyonların ve diğer bazı rahatsızlıkların iyileşme sürecini hızlandırıyor [4]. Benzer şekilde, çocuk ya da yetişkin fiziksel veya zihinsel engelliler ile herhangi bir nedenle hastanede tedavi gören her yaş gurubu bireylerin iyi olma halini desteklediğine dair çalışmalar da mevcuttur [21]. 
Bazı uzmanlara, tabiatın bu tedavi edici yönünü yeşil rengine bağlıyor. Zira renklerin insan psikolojisinde farkl1 etki oluşturduğu biliniyor [3]. Hatta yeşilin insanda güven ve rahatlama duygusu verdiği düşünülüyor. Terapi bahçelerine tasavvufi açıdan bakıldığında tabiat, Allah'ın isim ve sıfatlarının tecelli ettiği, insan fitratına uygun yaratılmış bir kitap niteliğinde görülür. İnsan tabiata baktıkça Rabbinin isimlerinin tecellilerini görüyor. Bu yüzden tabiatla baş başa kalan insan huzur bulur [27].

Sonuç olarak, TRSM'lerde bitki terapi bahçelerinin kullanımı ile hastaların toplumun dışına atılmadan ve dışlanmadan toplumla birlikte yaşamaları sağlanarak; yaşam kalitesini artırma ve bağımsızlığını kendi potansiyelinde en üst düzeye çıkarılmasına katkıda bulunacaktır. Bununla birlikte hem hastane yükü hafifleyecek dolayısıyla ülke maliyetleri azalacak hem de bu insanların topluma kazandırılması sağlanmış olacaktır. Bitki terapi bahçelerinin TRSM'lerde olduğu gibi, hastanelerde, yaşlı bakım evlerinde, özel eğitim ve rehabilitasyon merkezleri gibi bilhassa özel gereksinimi olan bireylerin bulunduğu mekanlarda terapi amaçlı kullanılması, ayrıca terapi bahçeleri ile ilgili yapılacak projelerin devlet tarafindan öncelikli alan olarak desteklenmesi önem arz etmektedir.

\section{KAYNAKLAR}

[1] Bozkurt SG Selçuklu ve Osmanlı Döneminde Darüşşifaların Avlu Özellikleri ve Avlularda Kullanılan Peyzaj Elemanları. Türk Bilimsel Derlemeler Dergisi. 2020; 13(1):32-41.

[2] Söderback I, Söderström M, Schälande E. Horticultural Therapy: THA Healing garden and Gardening in Rehabilitation Measures at Danderyd Hospital rehabilitation Clinic, Sweden. Pediatr Rehabil. 2004; 7(4):245-260.

[3] Yilmaz E. Hastanelerde Terapi Bahçelerinin İyi Olma Haline Etkilerinin Araştırılması. Yüksek lisans tezi. Fatih Sultan Mehmet Vakıf Üniversitesi Mühendislik ve Fen Bilimleri Enstitüsü; 2017.

[4] Ulrich RS, Simons RF, Losito DB, Fiorito E, Miles MA, Zelson M. Stress Recovery During Exposure to Natural and Urban Environments. J Environ Psychol. 1991; 11(3):201-230.

[5] Nicholson D. Green Cities-And Why We Need Them, New Economics Foundation Pocketbooks, United Kingdom; 2003.

[6] Chang CY. The Effects of Flowers on Respondents Physical and Psychological Responses. Interaction by Design: Bringing People and Plants Together for Health and WellBeing: An International Syposium (edited by Elizabeth R. Messer Diehl) Blackwell Publishing; 2002.

[7] Bilge A, Mermer G, Çam MO, Çetinkaya A, Erdoğan E, Üçkuyu N. Türkiye'deki Toplum Ruh Sağlığ1 Merkezlerinin 2013-2015 Yıllarının Profili. Kocaeli Üniversitesi Sağlık Bilimleri Dergisi. 2016; 2(2): 1-5.

[8] Tetik F, Civelek S, Cakilcioglu U. 2013. Traditional uses of some medicinal plants in Malatya (Turkey). J Ethnopharmacol. 2012; 146, 331-346.

[9] Saravia M, Ulisses A, Riberio D. Plant species as therapeutic resource in Savanna regionspernambuco state, northeastern Brazil. J Ethnopharmacol. 2015; 171:141-153.

[10] $\mathrm{Hu} \mathrm{R}$, Lin C, Xu W, Liu Y, Long C. Ethnobotanical study on medicinal plants used by Mulam people in Guangxi, China. J Ethnobiol Ethnomed. 2020;.2:16(1):40.

[11] Davis PH. Flora of Turkey and the East Aegean Islands. Edinburgh; Edinburgh Univ. Press; 19651985; Vol. 1-9, p.724.

[12] Davis PH, Mill RR, Tan K. Flora of Turkey and the East Aegean Islands (Supplement). Edinburgh; Edinburgh Univ. Press; 1988; Vol.10, p.590.

[13] Akkemik Ü. Türkiye'nin doğal-egzotik ağaç ve çalıları I, Gymnospermler-Angiospermler (A-G). Orman Genel Müdürlüğü Yayınları. Ankara, 2014a.

[14] Akkemik Ü. Türkiye'nin doğal-egzotik ağaç ve çalıları II, Angiospermler (H-Z). Orman Genel Müdürlüğü Yayınları. Ankara, 2014b.

[15] Yaltırık F, Efe A, Uzun A. İstanbul Adalarının Doğal ve Ekzotik Bitkileri. İst. Adaları İmar ve Kültür Vakfi; 1993. s.229.

[16] Trotter R, Logan M. İnformant consensus: a new approach for identifying potentially effective medicinal plants.in plants in indigenous Medicine and Diet: Biobehavioral Approaches, ed. Nina L. Etkin, Redgrave puplishers, Bedford Hills, NY; 1986. pp.91-112.

[17] Wang YH, Wang C. Common Ethnobotany Research Methods. Hangzhou: Zhejiang Education Publishing House; 2017.

[18] Kayani S, Ahmad M, Zafar M, Sultana S, Khan MPZ, Ashraf MA, Hussain J, Yaseen G. Ethnobotanical use of medicinal plants for respiratory disorders among those living in Gallies-Abbottabad, northern Pakistan. J Ethnopharmacol. 2014; 156: 47-60.

[19] Karasar N. Bilimsel Araştırma Yöntemi. Ankara: Nobel Yayınevi; 2005.

[20] Altay V, Karahan F. Tayfur Sökmen Kampüsü (Antakya-Hatay) ve Çevresinde Bulunan Bitkiler Üzerine Etnobotanik Bir Araştırma, KFBD. 2012; 2(7):13-28.

[21] Uslu A, Shakouri N. Zihinsel ve Fiziksel Engelliler İçin Hortikültürel Terapi. Kastamonu Üniversitesi, Orman Fakültesi Dergisi. 2012; 12 (1): 134-143

[22] Setenay Yar Z. Zihinsel ve Ruhsal Engelli Bireylere Yönelik Hortikültürel Terapi Bahçeleri: İzmirSeferihisar Kumrular Konakları Özel Bakım Merkezi Örneği. Yayınlanmamış Yüksek Lisans Tezi Bartın Üniversitesi Fen Bilimleri Enstitüsü Peyzaj Mimarlığı Anabilim Dalı; 2019.

[23] Jacquet A, Suresh R, Ghimire K, Rochet J. Nepalese traditional medicine and symptoms related to Parkinson's disease and other disorders: Patterns of the usage of plant resources along the Himalayan altitudinal range. J Ethnopharmacol. 2014; 153(1):178-89.

[24] Faruque MO, Uddin SB, Barlow JW, Hu S, Dong S, Cai Q, Li X and Hu XQ. Quantitative Ethnobotany of Medicinal Plants Used by Indigenous Communities in the Bandarban District of Bangladesh, Uantitative Ethnobotany of Medicinal Plants Used by Indigenous Communities in the Bandarban District of Bangladesh. Front. J Pharmacol. 2018; 9:40. 
[25] Polat R, Cakilcioglu U, Kaltalioğlu K., Ulusan MD, An Z. Ethnobotanical Study on Medicinal Plants in Espiye and its Surrounding (Giresun-Turkey) Türkmen. J Ethnopharmacol. 2015; 163, 1-11.

[26] Mimarlar HÇ. Şifa bahçelerinin terapik faydaları ve tasarım ilkelerinin belirlenmesi üzerine bir araştırma. Yayınlanmamış Yüksek Lisans Tezi. Uludağ Üniversitesi, Fen Bilimleri Enstitüsü; 2020.

[27] Okcu A. Kur'an'da Renkler. Atatürk Üniversitesi İlâhiyat Fakültesi Dergisi. 2007; 28: 127-163. 